\title{
Structural Insights into the Lithium Amide-Imide Solid Solution
}

\author{
Joshua W. Makepeace, ${ }^{1 *}$ and William I. F. David ${ }^{1,2 *}$ \\ ${ }^{1}$ Inorganic Chemistry Laboratory, University of Oxford, South Parks Road, Oxford, United Kingdom, OX13QR \\ ${ }^{2}$ ISIS Facility, Rutherford Appleton Laboratory, Harwell Campus, Didcot, United Kingdom, OXı1 oQX
}

\begin{abstract}
Solid solutions of lithium amide $\left(\mathrm{LiNH}_{2}\right)$ and lithium imide $\left(\mathrm{Li}_{2} \mathrm{NH}\right)$ are present during ammonia decomposition catalysis by lithium imide and hydrogen storage and release reactions in the lithium amide-lithium hydride composite. As such, they are important materials in facilitating the use of hydrogen as a sustainable energy store. In order to understand the properties of these solutions, a series of samples spanning the full stoichiometry range of the solid solution between lithium amide and lithium imide was synthesised. Powder diffraction measurements showed that a nonstoichiometric cubic phase isostructural to the high temperature phase of lithium imide was observed in all of the samples. In average stoichiometry values close to lithium amide, incomplete formation of a solid solution was observed, with tetragonal lithium amide observed in addition to the cubic non-stoichiometric phase. In analysis of neutron diffraction data, the variable stoichiometry in the structure was modelled using a "golf-ball" of scattering density around the nitrogen atom. This analysis revealed a greater degree of disorder in hydrogen distribution in the non-stoichiometric samples compared with lithium imide. Raman spectroscopy indicated that amide and imide groups in stoichiometric and nonstoichiometric environments can be differentiated by the frequency of the $\mathrm{N}-\mathrm{H}$ stretch, with distinct bands observed for both amide and imide $\mathrm{N}-\mathrm{H}$ stretches in both environments.
\end{abstract}

\section{INTRODUCTION}

The significant potential for hydrogen to be used as a sustainable fuel for transportation and inter-seasonal grid balancing - its high gravimetric energy density and benign oxidation emissions - have been vexed by the inability to store hydrogen in a volumetrically dense form. Physical storage in high pressure tanks or cryogenic systems is an expensive and energy intensive solution, which has prompted the search for appropriate systems for the chemical storage of hydrogen. One such approach is the use of a solid material which reacts with hydrogen to store it as part of a new material.

Among the materials that store hydrogen in this way, composites of light metal amides and metal hydrides have been shown to be one of the most promising material families for practical application ${ }^{1,2}$. Many solid state hydrogen stores can store impressive quantities of hydrogen (towards $20 \mathrm{wt} \%$ ), but relatively few can do so reversibly, which precludes them from most practical use. However, the lithium amide - lithium hydride composite has been demonstrated to reversibly store around $6 \mathrm{wt} \%$ hydrogen at $250^{\circ} \mathrm{C}$ and a hydrogenation pressure of 2 bar over hundreds of cycles 3,4 . Although the reaction kinetics are currently slower than are required for transport applications, this system is an excellent model for facile reversibility in chemical hydrogen storage materials. The storage of hydrogen in this system is based on the reaction of lithium amide and lithium hydride to form lithium imide with the release of hydrogen:

$$
\mathrm{LiNH}_{2}+\mathrm{LiH} \rightarrow \mathrm{Li}_{2} \mathrm{NH}+\mathrm{H}_{2}
$$

The reversibility of the system is underpinned by the structural similarity of the amide and imide phases. Lithium amide can be considered as an $a \times a \times 2 a$ supercell of lithium imide where an ordered half of the lithium sites are vacant (see Figure 1). Thus, the dehydrogenation of lithium amide, according to Equation 1, results in the filling of these vacant lithium sites as hydrogen is released from the structure. This process results in the formation of a solid solution as the system transforms between the amide and imide. This process was rationalised on the atomic scale as the formation of Frenkel defect pairs ${ }^{5}$ the movement of lithium ions into vacant tetrahedral sites in the structure (the red sites in Figure 1c). The local charge imbalance caused by this migration can be addressed by the transfer of protons between $\mathrm{NH}_{2}{ }^{-}$groups. These shuttled protons are then able to react with hydride ions in lithium hydride, releasing hydrogen. This mechanism has been supported by first-principles density functional theory (DFT) calculations ${ }^{6,7}$.

This mechanism was proposed on the basis of synchrotron X-ray diffraction measurements of cycled lithium amide-lithium hydride samples. Subsequent experimental studies $^{8,9}$ have expanded the understanding of this process, showing that during hydrogen storage and release reactions, the lithium amide-imide system is well 
a)
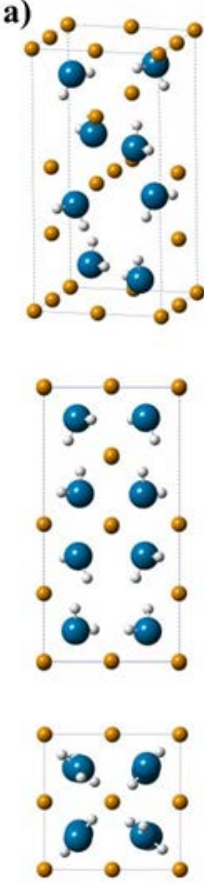

b)

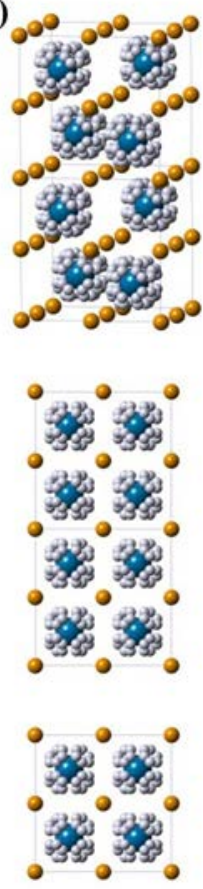

c)

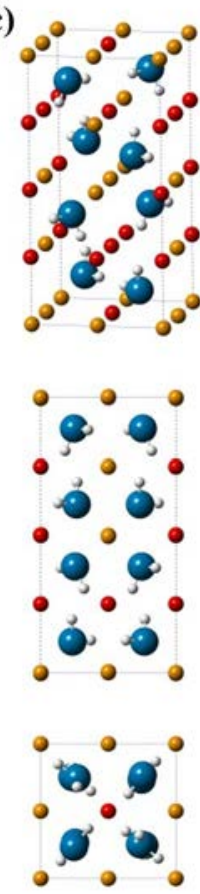

Figure 1. Crystal structures of a) lithium amide b) lithium imide $(\mathrm{a} \times \mathrm{a} \times 2 \mathrm{a}$ supercell $)$ and $\mathrm{c})$ lithium amide with vacant tetrahedral sites shown in red to show relationships between the amide and imide structures. Lithium atoms are shown in orange, nitrogen in blue and hydrogen in white. Each structure is shown (top) from an offset perspective, (middle) viewed along the $a$ axis, and (bottom) viewed along the $c$ axis.

described by a solid solution spanning the range of stoichiometry between lithium amide and lithium imide, $\mathrm{Li}_{1+x} \mathrm{NH}_{2-x}(0<x<1)$. The presence of this solid solution is key to the facile reversibility of the hydrogen storage reaction.

In addition to storing hydrogen itself, lithium imide has been shown to have high activity in the catalytic decomposition of ammonia to hydrogen and nitrogen ${ }^{10}$. Ammonia has many attractive characteristics as a hydrogen store: it is easily liquefied at around $10 \mathrm{~atm}$, and in this state has an energy density roughly $40 \%$ that of petrol. However, the low-temperature release of hydrogen from ammonia is a key challenge which requires the development of new catalysts. Lithium imide shows comparable catalytic activity to the most active transition metal catalysts. Neutron powder diffraction measurements under ammonia decomposition conditions showed that the catalyst exists in a non-stoichiometric state, with the precise stoichiometry dependent on the reaction conditions ${ }^{10}$. Understanding the amide-imide solid solution is an important component of an investigation into the catalytic reaction mechanism.

The existence and behaviour of this solid solution is thus of significance for the use of lithium amide-imide in hydrogen energy applications. However, relatively few investigations have examined its properties. A DFT study of the system by Zhang et al. suggested that non-

stoichiometric phases would be stable for values of $x$ greater than 0.75 and unstable for values less than 0.25 , predicting phase separation into lithium amide and lithium imide ${ }^{11}$. This study also predicted that the discrete $\mathrm{Li}_{1.5} \mathrm{NH}_{1.5}$ phase, which had been hypothesised from experimental $^{12}$ and computational ${ }^{13}$ studies, was not thermodynamically stable at o K. A recent investigation of a series of partially-dehydrogenated lithium amide-lithium hydride mixtures reported ionic conductivity data for the non-stoichiometric phases as varying steadily between lithium amide and lithium imide as the extent of dehydrogenation increased ${ }^{14}$.

Further experimental and computational data on the properties of the lithium amide-imide solid solution would help elucidate the precise role of the solid solution in hydrogen storage and ammonia decomposition applications. The aim of this study is to provide some initial experimental data on the synthesis of a range of nonstoichiometric samples and the structural and bonding variation across those samples as a function of average stoichiometry.

\section{EXPERIMENTAL}

Sample Preparation. Sample manipulation was performed in an argon-filled glove box (MBraun Unilab, $\mathrm{O}_{2}$ and $\mathrm{H}_{2} \mathrm{O}<0.1 \mathrm{ppm}$ ). Non-stoichiometric lithium amideimide samples were prepared by the reaction of lithium nitride (98\%, Sigma Aldrich) and lithium amide (98\%, Sigma Aldrich), as reported by $\mathrm{Hu}$ and Ruckenstein for the synthesis of lithium imide ${ }^{15}$ :

$$
\mathrm{Li}_{3} \mathrm{~N}+\mathrm{LiNH}_{2} \rightarrow 2 \mathrm{Li}_{2} \mathrm{NH}
$$

This reaction was chosen (in preference to the reaction of $\mathrm{LiNH}_{2}$ and $\mathrm{LiH}$ or of $\mathrm{Li}_{2} \mathrm{NH}$ with $\mathrm{NH}_{3}$ ) as the relatively low temperatures used in this method minimise the potential for phase separation of the non-stoichiometric phases (as had previously been observed after annealing at high temperature ${ }^{9}$ ) and/or the loss of ammonia from the system. Furthermore, the precise stoichiometry could be targeted simply through the ratio of the solid reactants, rather than having to quench a solid-gas reaction. The ratio of lithium amide to lithium nitride was altered to synthesise non-stoichiometric samples with a narrow stoichiometric distribution, according to Equation 3.

$$
(x) \mathrm{Li}_{3} \mathrm{~N}+(2-x) \mathrm{LiNH}_{2} \rightarrow 2 \mathrm{Li}_{1+x} \mathrm{NH}_{2-x}
$$

The powdered reactants were measured out in a molar ratio to give the desired stoichiometry $\left(\mathrm{Li}_{1+x} \mathrm{NH}_{2-x}\right.$, where $x$ $=0^{-1}$ in steps of 0.1 ), and were hand ground for five minutes using an agate mortar and pestle. The mixture was then placed inside a $125 \mathrm{~mL}$ tungsten carbide milling jar, filled with nine, 10-mm diameter tungsten carbide milling balls. The jar was sealed and placed onto a planetary mill (PMioo, Retsch). The sample was milled for two 
hours at 400 rpm, with the milling time split into $15 \mathrm{mi}-$ nute sections with two minute rest periods between each section. The direction of milling rotation was reversed after each segment.

After milling, the resultant powder was placed into a cylindrical alumina crucible held within a quartz tube. Argon gas was flowed over the tube outlet using a glass Tpiece fitted with Young's taps. Each sample was heated to $250{ }^{\circ} \mathrm{C}$ at a heating ramp of $2{ }^{\circ} \mathrm{C} / \mathrm{min}$ and then held at that temperature for 12 hours. After removal from the crucible, the sample was hand ground prior to analysis.

X-ray Powder Diffraction. X-ray powder diffraction patterns were collected using a Rigaku Smartlab Diffractometer, fitted with a copper source and monochromator. Samples were loaded into $0.7 \mathrm{~mm}$ i.d. borosilicate capillaries and mounted on the diffractometer. X-ray diffraction data were collected with rotation of the capillary for one hour per sample between $10^{\circ}$ and $70^{\circ}$. The resultant diffraction patterns were analysed by the Rietveld method using the TOPAS Academic Version 5 least-squares fitting software.

Neutron Powder Diffraction. Neutron powder diffraction data were collected on the POLARIS instrument at the ISIS Neutron and Muon Facility in the United Kingdom. Deuterated samples of the non-stoichiometric phases $(\mathrm{x}=0.1,0.3,0.5,0.7,0.9)$ were prepared by the same method as outlined for the other samples, except using deuterated lithium amide. This was prepared by the reaction of lithium nitride with deuterated ammonia (98 atom $\%$ D, CKGas). The lithium nitride was exposed to 3 bar of ammonia and heated to $300{ }^{\circ} \mathrm{C}$ at a ramp rate of $2{ }^{\circ} \mathrm{C} / \mathrm{min}$. The sample was held at that temperature for 3 hours before being cooled and collected. The samples were placed in $6 \mathrm{~mm}$ diameter cylindrical vanadium cans and sealed with indium wire. Neutron diffraction data were collected for 2 hours per sample. The diffraction patterns were analysed using TOPAS Academic Version 5.

Raman Spectroscopy. Raman spectra of the nonstoichiometric phases were collected using a Bruker Senterra Raman microscope. Samples were loaded into $0.7 \mathrm{~mm}$ i.d. borosilicate capillaries. Raman spectra were recorded using $532 \mathrm{~nm}$ laser in two, two-second exposure periods. The resultant Raman spectra were analysed using TOPAS Academic Version 5, with the Raman peaks modelled as a series of pseudo-Voigt functions.

\section{RESULTS AND DISCUSSION}

Selected sections of the X-ray powder diffraction patterns of the samples are shown in Figure 2a, with the results of Rietveld analysis of the patterns summarised in Figure $2 \mathrm{~b}$ and $2 \mathrm{c}$. Each of the samples (other than pure lithium amide) shows the presence of a cubic phase which is isostructural with the high temperature phase of lithium imide. This phase is consistent with the phase previously observed during hydrogenation and dehydrogenation of the lithium amide - lithium hydride composite. These imide-like phases do not appear to adopt the low temperature lithium imide structure $(F d \overline{3} m)^{16}$, as evi- denced by the lack of the (111) peak of the lowtemperature phase at $2 \theta=15^{\circ}$. This may reflect a larger degree of disorder in the non-stoichiometric structures the same phase has also been observed in room temperature X-ray powder diffraction patterns of partiallydehydrogenated samples of lithium amide-lithium hydride ${ }^{14}$.

Although this cubic phase is the major crystalline component of every sample except $\mathrm{Li}_{1.1} \mathrm{NH}_{1.9}$, unreacted starting materials exist in a number of the samples (Figure $2 \mathrm{~b}$ ). The non-stoichiometric samples closest to lithium amide stoichiometry have a significant proportion of lithium amide present, while those with an average stoichiometry closer to lithium imide have small quantities of lithium nitride present. While the low levels of lithium nitride may indicate incomplete mixing of the starting materials, the larger quantities of lithium amide observed in the diffraction data are more likely to indicate the incomplete formation of the solid solution. The only other explanation would be that the tetragonal phase exists across a broader stoichiometry range than was observed in the insitu data9. An oscillation in the extent of solid solution formation across samples $\mathrm{Li}_{1.1} \mathrm{NH}_{1.9}$ to $\mathrm{Li}_{1.5} \mathrm{NH}_{1.5}$ appears to be correlated with oscillation of the magnitude of the $c$ lattice parameter of the lithium amide, which may indicate stoichiometry-dependent behaviour. However, the refined a lattice parameter of the tetragonal phase does not show a clear trend across the samples (Figure 2c). Thus, it is difficult to ascertain the degree of stoichiometry variation accommodated within the lithium amide structure.

While it is clear from the data that the solid solution can be formed across a range of average stoichiometry values, these results may indicate that the solution is unstable close to the stoichiometry of lithium amide, as was postulated by Zhang et $\mathrm{al}^{11}$. Some instability of the solid solution to annealing was also reported in the synchrotron X-ray powder diffraction study, although the formation of tetragonal lithium amide was not observed as the result of this ordering process9.

One further explanation for the presence of lithium amide impurities relates to the synthesis procedure. Upon the reaction of lithium nitride and lithium amide to form lithium imide, the subsequent formation of a bulk solid solution requires the diffusion of lithium and hydrogen ions through the structure. Lithium amide is a poor lithium ion conductor ${ }^{17}$, and so it is possible that the temperatures used in these synthesis reactions were insufficient to enable bulk formation of the non-stoichiometric phase in samples which contained a significant proportion of lithium amide. This analysis is supported by the fact that lithium nitride, which is a very good lithium ion conductor ${ }^{18}$, did not appear in large quantity in any of the phases. This also suggests that the initial exchange of cations (insertion of lithium into and removal of hydrogen from the lithium amide structure) proceeded, but the formation of a uniform non-stoichiometric phase was retarded by the poor lithium ion conductivity of the amide/amide-like structure. Repetition of this experimental work at higher 


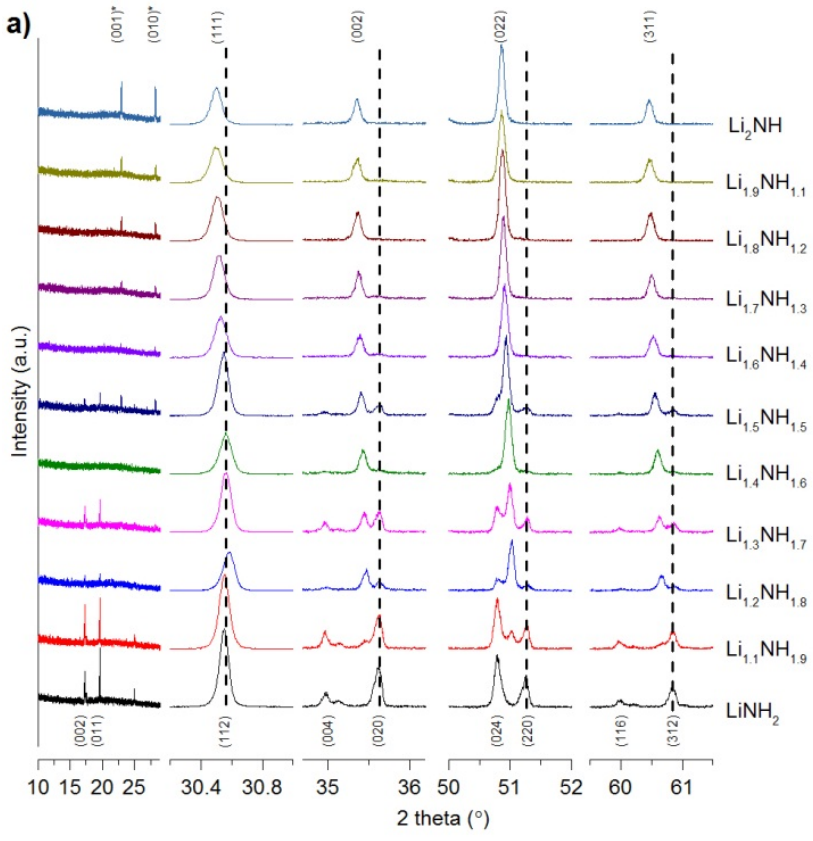

b)
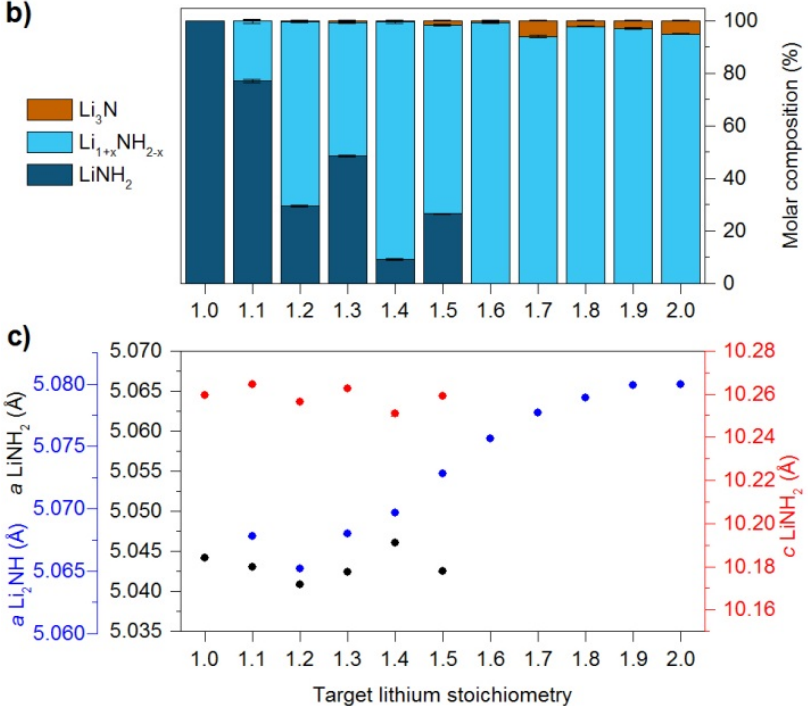

Figure 2. a) Sections of X-ray powder diffraction patterns of each of the lithium amide-imide samples, with the average stoichiometry indicated beside each pattern. Selected Miller indices for the lithium amide and $\mathrm{Li}_{1+\mathrm{x}} \mathrm{NH}_{2-\mathrm{x}}$ phases are shown below and above the patterns, respectively. The starred Miller indices are from alpha lithium nitride. b) The molar composition of each sample (with lithium amide and imide also included for reference) as determined by Rietveld analysis of the powder diffraction data, along with c) the lattice parameters of the $\mathrm{LiNH}_{2}$ and $\mathrm{Li}_{1+x} \mathrm{NH}_{2-x}$ phases, with error bars representing one standard deviation contained within the data points.

temperatures or with more intense milling conditions could help to elucidate whether this effect is the cause of these results.

The steady variation in the lattice parameter of the cubic phase indicates the successful formation of solid solutions of a range of average stoichiometry values, despite the presence of the impurities discussed above. The peak shapes of Bragg peaks associated with the non- stoichiometric cubic phases in these patterns do not exhibit the same complex structure as was observed in the in-situ powder diffraction studies, although higher resolution diffraction data were collected in those studies ${ }^{5,9}$.

The variation in the lattice parameter $(\sim 0.3 \%)$ is of a similar magnitude to that seen for the full range of stoichiometry values in the in-situ diffraction experiments, indicating that a reasonably wide range of stoichiometry values were synthesised. However, the lattice parameters of the non-stoichiometric phases increase as the stoichiometry approaches lithium imide, which is the opposite trend to that which was observed in the hydrogen storage and release reactions of the $\mathrm{Li}-\mathrm{N}-\mathrm{H}$ system detailed insitu ${ }^{9}$.

Previous structural studies of lithium imide, which have generally reported a larger $a$ lattice parameter for lithium imide than lithium amide, have all synthesised lithium imide by thermal decomposition of lithium amide in,16,19,20 $^{\text {. }}$ On the other hand, studies of the lithium amide-lithium hydride hydrogen storage system show a decrease in the $a$ lattice parameter of "lithium imide" as the dehydrogenation proceeded ${ }_{5,8,9,21,22}$. It is clear that the method of preparing these materials has a significant effect of their microstructure, with the lattice parameter variation possibly reflecting different defect structures.

Because of the weak X-ray scattering from hydrogen and lithium, it was not possible to directly refine the stoichiometry of the cubic phase from the powder X-ray diffraction data. Therefore, a series of deuterated nonstoichiometric phases were synthesised and analysed by neutron powder diffraction. The general structural trends indicated by the neutron diffraction data, shown in section in Figure 3a, and the sample compositions obtained by Rietveld analysis of the diffraction data (Figure $3 \mathrm{~b}$ ) show a general agreement with the X-ray diffraction experiments.

The strong neutron scattering exhibited by deuterium allowed for the refinement of the sample stoichiometry directly from the diffraction data. Although the deuterium positions in the high temperature phase of lithium imide have been investigated in some detail by Balogh et al. ${ }^{16}$, changes in those positions with varying stoichiometry have not yet been reported. In order to create as general a model as possible and to allow for increased disorder in the mixed-anion systems, a roughly spherical distribution of 194 deuterium positions (9 crystallographically distinct sites) was generated around the nitrogen atom in the lithium imide structure, shown in Figure $3 \mathrm{c}$.

The occupancy of each site was controlled in the Rietveld analysis by oth, 4th, 6th and 8th order spherical harmonic terms, which increase or decrease the occupancy along certain crystallographic directions (see Supporting Information). The lithium occupancy was calculated on the basis of the total deuterium occupancy in order to ensure that charge was balanced. The refined deuterium occupancies are shown in Figure 3d, viewed along the (100), (110) and (111) directions. These results show that, in agreement with the previous neutron diffraction 

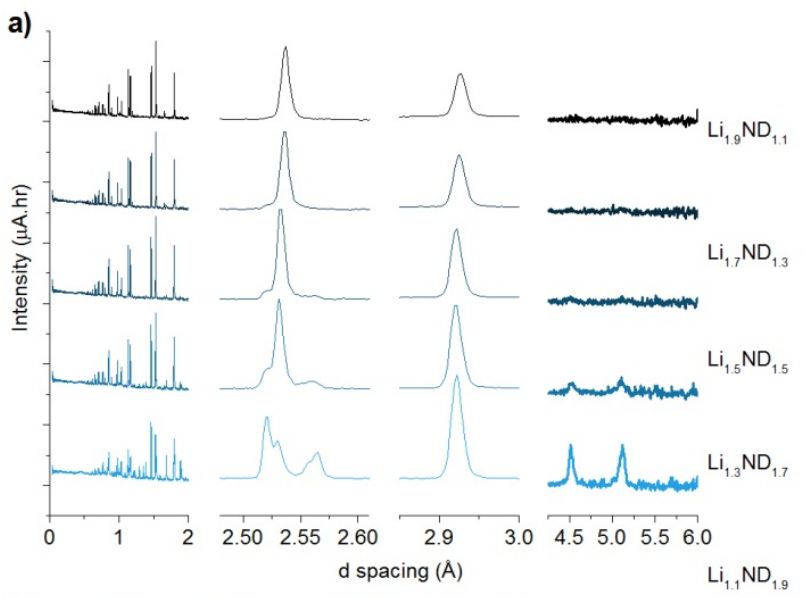

b)

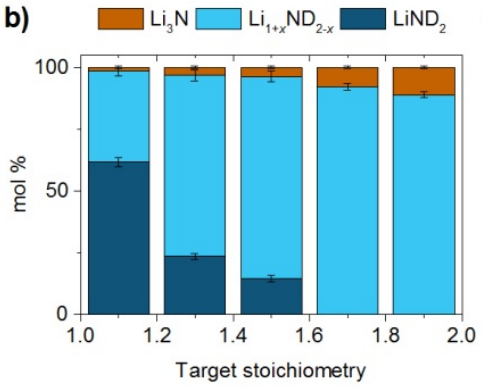

c)

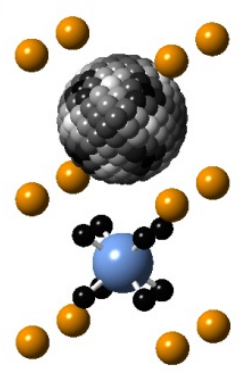

d) 1
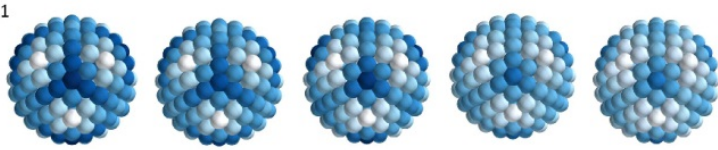

100
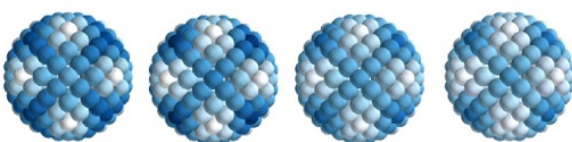

110
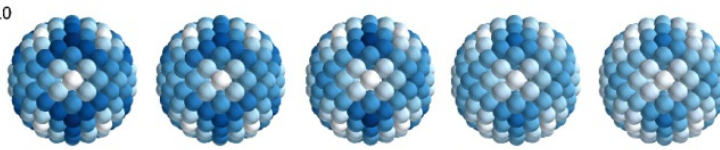

$\mathrm{Li}_{1.33} \mathrm{ND}_{1.67}$

$\mathrm{Li}_{1.42} \mathrm{ND}_{1.58}$
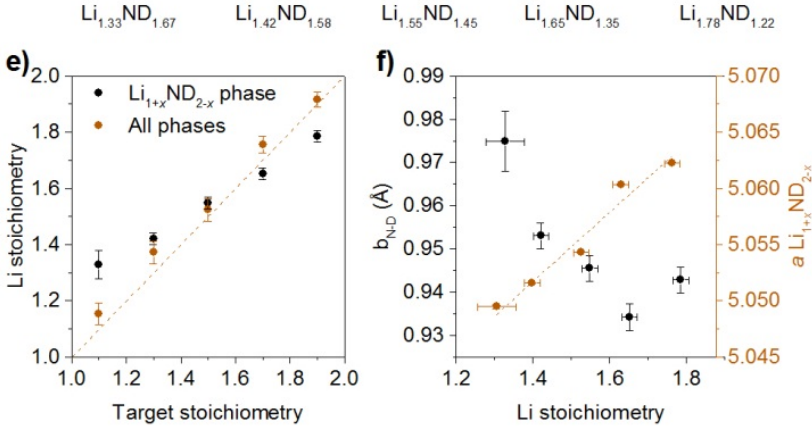

Figure 3. a) Selected regions of neutron powder diffraction patterns for each of the synthesised non-stoichiometric phases. The data shown for the d-spacing regions $0.5^{-2.0} \AA$ and 2.4-2.65 $\AA$ are from the bank 5 detectors, 2.85-3.0o $\AA$ are from bank 4, and 4.25-5.50 $\AA$ are from bank 3, b) molar composition of the samples, c) the structural model of the imideamide anion used, with deuterium positions shown in grayscale, lithium shown in orange and nitrogen in blue. The top anion shows the full sphere of deuterium positions used, while the bottom shows only the (111) deuterium positions d) orientational distributions of the deuterium occupancies for each sample viewed along the 100, 111 and 110 directions, with the refined occupancy of the sample shown below; darker blue indicates higher occupancy of the site, with the colour scale normalised across the samples, e) a comparison of the target lithium stoichiometry with the lithium stoichiometry of the non-stoichiometric phase and the total refined stoichiometry of the sample (i.e. including all crystalline phases) and $f$ ) the variation of the N-D bond length and the lattice parameter with the lithium stoichiometry of the nonstoichiometric phase. Error bars represent one standard deviation.

studies of lithium imide, the highest deuterium occupancy is along the (111) direction. The somewhat counterintuitive location of the most preferred $\mathrm{N}-\mathrm{H}$ bond orientation being towards the lithium sites has been explained by Miceli et al..$^{23}$ as a reflection of the presence of lithium vacancies in the structure similar to those in the muchdiscussed low temperature phase of lithium imide in-27, $^{24}$ where imide anions arrange in tetrahedral coordination around vacant lithium sites which correspond to imide groups pointing in the (111) direction. Miceli et al propose that the high temperature structure resembles one of the early models of the low temperature structure ${ }^{24}$, but that the fast diffusion of the lithium ions results in the observed $F m \overline{3} m$ structure. However, the "golf-ball" model used here reveals that there is more disorder in the orientation of the anions in these non-stoichiometric phases. Significant occupancy was obtained in the sites close to the (100) direction, while sites along the (110) direction returned very low deuterium occupancy values. Aside from the steady variation in the total deuterium content, only minor differences were observed in the pattern of $\mathrm{N}$ $\mathrm{D}$ bond orientation across the stoichiometry range, as evidenced by the slight variations in the spherical harmonics coefficients (see Supporting Information).

The refined stoichiometry values of the cubic phase and the total lithium stoichiometry of the sample (from the sum of the cubic phase, lithium nitride and lithium amide) are shown in Figure ze. There is good agreement between the sample stoichiometry and the target stoichiometry, indicating that the structural model used in the Rietveld analysis is reasonable. The lattice parameter of the cubic phase varies linearly with the refined lithium stoichiometry, which is consistent with Vegard's Law behaviour. The average N-D bond length is close to that reported for lithium amide ${ }^{28,29}$ in the $\mathrm{Li}_{1.1} \mathrm{ND}_{1.9}$ sample, decreasing as the average stoichiometry approached lithium imide to a slightly shorter bond length than has been reported for lithium imide by Balogh et $\mathrm{al}^{16}$.

The orientational distribution of the N-D bond was explored further by subtracting the occupancy values obtained for the most imide-like sample $\left(\mathrm{Li}_{1.78} \mathrm{ND}_{1.22}\right)$ from the remaining samples. This should leave only the deuterium occupancy values associated with the amide groups in those samples. The N-D spheres obtained from this analysis are shown in Figure 4. For every sample except $\mathrm{Li}_{1.55} \mathrm{ND}_{1.45}$, the maximum deuterium occupancy was just away from the 111 direction in a configuration which is consistent with that of the amide units in lithium amide (which point towards vacant tetrahedral sites). All of the 
a)

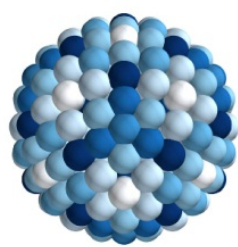

c)

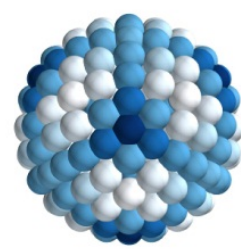

b)

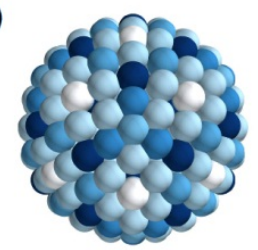

d)

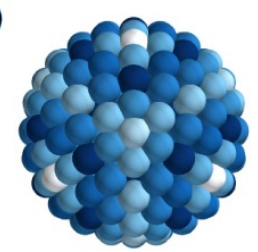

Figure 4. N-D orientational distributions with the imide component subtracted for a) $\mathrm{Li}_{1.33} \mathrm{ND}_{1.67}$ b) $\mathrm{Li}_{1.42} \mathrm{ND}_{1.58}$ c) $\mathrm{Li}_{1.55} \mathrm{ND}_{1.45}$ and d) $\mathrm{Li}_{1.78} \mathrm{ND}_{1.22}$. Darker blue indicates higher occupancy of the site, with the colour scale normalised for each sample.

distributions suggest some disorder in the amide group orientations. Indeed, the $\mathrm{Li}_{1.55} \mathrm{ND}_{1.45}$ amide-only orientational distribution remains very similar to the distribution observed for the whole sample.

As a complement to the structural investigation, the bonding in the amide and imide anions was probed by Raman spectroscopy, with the $\mathrm{N}-\mathrm{H}$ stretching region for each of the samples shown in Figure 5, along with those of lithium amide and lithium imide, for reference.

Lithium amide shows characteristic vibrations for an $\mathrm{NH}_{2}$ unit: the large peak at $3260 \mathrm{~cm}^{-1}$ is the symmetric $\mathrm{N}-$ $\mathrm{H}$ stretch band, while the two smaller peaks at 3313 and $3323 \mathrm{~cm}^{-1}$ are the asymmetric $\mathrm{N}-\mathrm{H}$ stretches. The linear imide ion, on the other hand, only exhibits one main $\mathrm{N}-\mathrm{H}$ stretch, the broad band at $3185 \mathrm{~cm}^{-1}$, with a small additional peak at $3244 \mathrm{~cm}^{-1}$. These spectra are consistent with previously reported results $3^{30-32}$.

Examination of Figure 5a shows that the transition through the range of average stoichiometry values does not result in a simple linear decrease in the amide peaks with a concomitant increase in the imide peak. Additional peaks are observed in the spectra, similar to those reported recently by Paik et al. ${ }^{14}$, which are most pronounced in the intermediate stoichiometry range. Fitting of the data provides some insight into the composition of the spectra, with the best fit obtained by the inclusion of three additional N-H stretch peaks (i.e. a total of seven $\mathrm{N}-\mathrm{H}$ stretch bands). The positions of each of the peaks are indicated as dashed lines in Figure $5 a$ and an example of the contributions of each peak to the overall fit to the data is shown in Figure 5b. One low intensity peak occurs between the symmetric and asymmetric amide stretch bands (at around $3280 \mathrm{~cm}^{-1}$ ), and the shoulder of the symmetric amide stretch is fitted to two peaks (around 3230 and 3250 $\mathrm{cm}^{-1}$ ).

The relative peak areas for each of the refined peaks are shown in Figure $5 \mathrm{c}$. The top panel details the peak areas of the amide and imide $\mathrm{N}-\mathrm{H}$ stretches for the various

samples, which broadly reflect what would be expected of the transition from lithium amide to lithium imide through mixed phases. The bottom panel details the peak areas of the three unknown peaks (Unknown 1-3). From this plot, it is clear that Unknown 2 and Unknown 3 are related peaks which are most prevalent in the imide-like samples. Conversely, Unknown 1 appears to be associated with a different motif that is present in the amide-like samples. The relative energies and intensities of Unknowns 2 and 3 are similar to those of the lithium amide symmetric and asymmetric $\mathrm{N}-\mathrm{H}$ stretch bands, and so are tentatively assigned as a second set of amide stretches: Unknown 2 as the symmetric stretch and Unknown 3 as the combination of the two asymmetric stretches. It is therefore suggested that Unknown 1 is a second imide $\mathrm{N}$ $\mathrm{H}$ stretch.

The appearance of a second set of amide and imide N$\mathrm{H}$ stretches in the non-stoichiometric phases could be indicative of a second chemical environment for the anions. This would be consistent with the local formation of a non-stoichiometric phase, as the change in lithium ion density around the anions with stoichiometry variation would undoubtedly have an effect on the strength of the $\mathrm{N}-\mathrm{H}$ bonds, and hence the frequency of the vibration of those bonds. On this basis, it is hypothesised that the unknown peaks are associated with amide/imide units in an environment which has deviated from stoichiometric lithium amide/imide. If this is the case, the fact that there remains a significant signal from the original amide $\mathrm{N}-\mathrm{H}$ stretches in the lithium-poor phases $(\mathrm{x} \leq 0.5)$ is consistent with the X-ray and neutron powder diffraction data in indicating that these phases contain crystalline domains of tetragonal lithium amide. The broader peaks observed in the second set of amide stretches may indicate a greater degree of disorder in the environment of these amide anions. This is consistent with their presence in a nonstoichiometric phase.

A summary of the various $\mathrm{N}-\mathrm{H}$ stretching peaks described is given in Table 1 . The positions of the lithium imide $\mathrm{N}-\mathrm{H}$ stretch, and the three intermediate peaks, all vary with changing value of $x$, with a consistent magnitude of change across all four peaks. This indicates that the shift in wavenumber in all of these peaks is associated with a common change in chemical environment. Indeed, computational analysis has indicated that the bond strength of the $\mathrm{N}-\mathrm{H}$ bond in the imide anion is weaker than in the amide anion ${ }^{33}$. Thus, it is reasonable to suggest that the bond strength of an $\mathrm{N}-\mathrm{H}$ bond would decrease as the stoichiometry moves from amide to imide, consistent with the data shown in Figure 5. These peak shifts support the assertion that the unknown peaks are due to the non-stoichiometric phases. They also suggest that the imide $\mathrm{N}-\mathrm{H}$ stretch at $3185 \mathrm{~cm}^{-1}$ may not be due simply to stoichiometric lithium imide, but are attributable to non-stoichiometric imide units. If this is the case, then it could be asserted that the unknown 1 peak could represent imide units in an amide-like environment. In contrast, the amide $\mathrm{N}-\mathrm{H}$ stretch peaks show only a very small change in wavenumber with changing stoichiome 

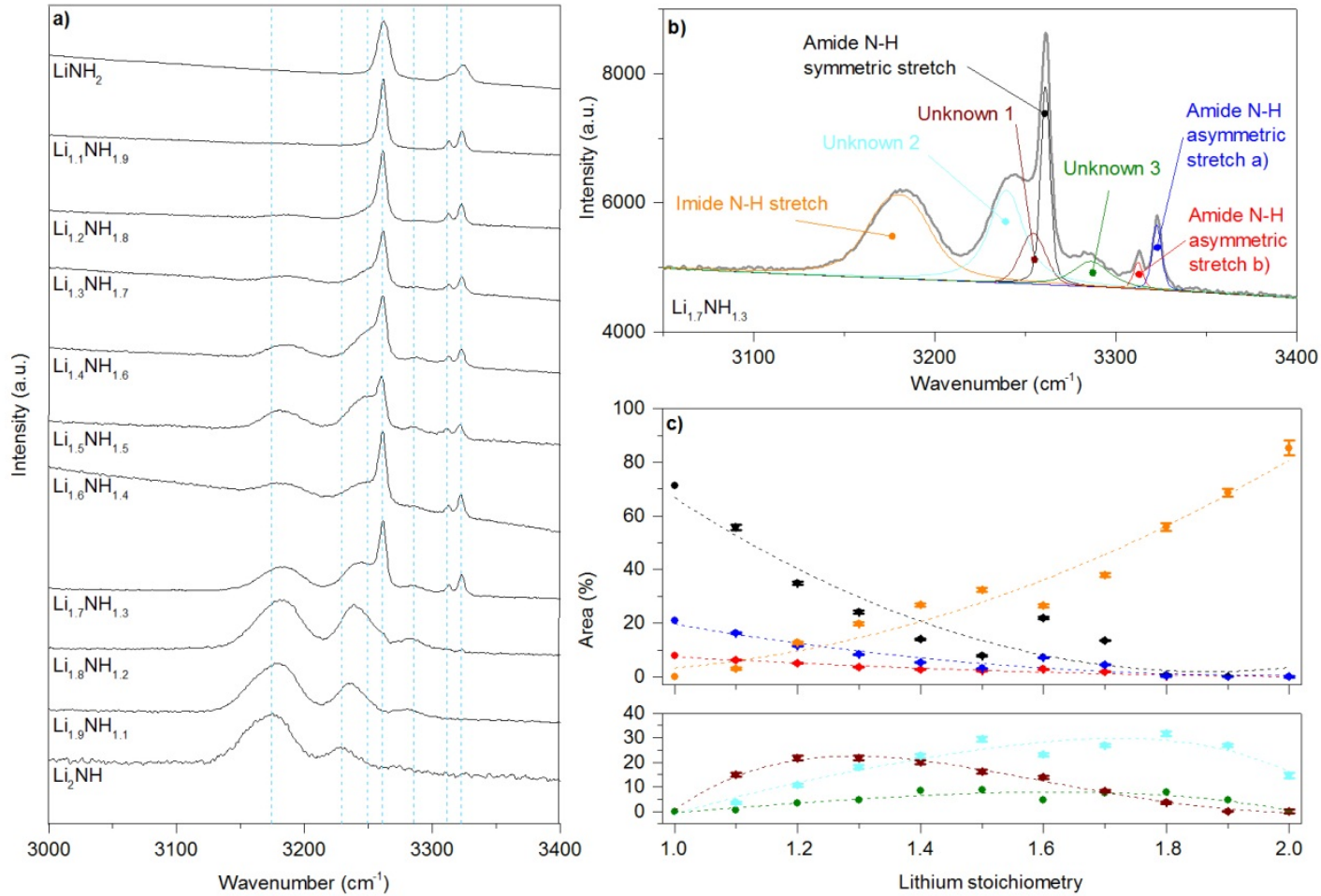

Figure 5. a) The N-H stretch region of the Raman spectra obtained for each of the phases synthesised in the continuum between lithium amide and lithium imide. The dashed vertical lines indicate the approximate position of the peaks assigned, which are shown in more detail in b), an example of the fit to the data for the $\mathrm{Li}_{1.7} \mathrm{NH}_{1.3}$ average stoichiometry sample showing the contribution of each fitted peak to the total spectrum. Relative peak areas for each of the refined peaks in the Raman spectra of the lithium amide - imide continuum are shown in c), with polynomial fits to the data included as dashed lines.

try, again supporting the assertion of the presence of a stoichiometric lithium amide phase in these samples.

If complete formation of the solid solution were achieved across the full stoichiometry range, it would be expected that a single set of amide and imide $\mathrm{N}-\mathrm{H}$ stretches would be observed in the Raman spectrum, with the peak area changing linearly with stoichiometry. What can be inferred from the data shown in Figure 5 is that under the synthesis conditions used in this study, the amide/imide ions enter nonstoichiometric phases when the overall stoichiometry is far from their respective line phases, but as the stoichiometry approaches one of the end members, the relative anion tends to order into the line phase (this effect is exaggerated for the imide, which appears to show stoichiometry variation in its 'line phase' $\mathrm{N}-\mathrm{H}$ stretch peak as discussed above). This is consistent with the results from the in-situ diffraction study, which showed that the intermediate phases were unstable with regard to separation into lithium amide and lithium imide. The fact that multiple $\mathrm{N}-\mathrm{H}$ stretch signals were observed in samples where only a single phase was observed in the diffraction data highlights the potential for local structure variations in these materials.

\section{CONCLUSIONS}

The lithium amide-imide solid solution appears to play a functional role in the hydrogen storage reactions of the lithium amide-lithium hydride composite, and is the ac- tive form of the lithium imide ammonia decomposition catalyst. The structural and spectroscopic investigation of this solution presented in this work will form the basis of an enhanced understanding of the precise structureproperty relationships in these energy storage applications.

Samples of the lithium amide-imide solid solution with a range of average stoichiometry values were synthesised and characterised by X-ray and neutron powder diffraction. For samples with average stoichiometry close to lithium imide, the synthesis methodology resulted in the formation of a single phase isostructural with high temperature lithium imide. Samples with an average stoichiometry close to lithium amide were found to be a mixture of the tetragonal lithium amide structure and the cubic imide-like structure.

There was no evidence for significant variation in stoichiometry in the tetragonal lithium amide structure, whereas the imide-like structure exhibited a range of stoichiometry values, as evidenced by changes in the lattice parameter and refined lithium occupancy across all of the samples. Opposite trends in the change in lattice parameter with stoichiometry in this study compared with previous in-situ experiments on the Li-N-H hydrogen storage system indicate potential differences in the microstructure of the solid solution depending on the synthesis method. 
Table 1 - N-H stretch peaks observed in the nonstoichiometric $\mathrm{Li}-\mathrm{N}-\mathrm{H}$ samples.

\begin{tabular}{|c|c|c|c|}
\hline Peak & $\begin{array}{l}\text { Position } \\
\left(\mathbf{c m}^{-1}\right)\end{array}$ & $\begin{array}{l}\text { Position } \\
\text { change per } \\
\text { o.1x }\left(\mathrm{cm}^{-1}\right)\end{array}$ & Phase \\
\hline $\begin{array}{l}\mathrm{NH}_{2} \\
\text { symmetric }\end{array}$ & 3260 & $-0.340(5)$ & $\begin{array}{l}\text { Stoichiometric } \\
\text { lithium amide }\end{array}$ \\
\hline $\begin{array}{l}\mathrm{NH}_{2} \\
\text { asymmetric }\end{array}$ & 3313 & $-0.340(5)$ & $\begin{array}{l}\text { Stoichiometric } \\
\text { lithium amide }\end{array}$ \\
\hline $\begin{array}{l}\mathrm{NH}_{2} \\
\text { asymmetric }\end{array}$ & 3323 & $-0.340(5)$ & $\begin{array}{l}\text { Stoichiometric } \\
\text { lithium amide }\end{array}$ \\
\hline $\mathrm{NH}$ & 3185 & $-2.78(4)$ & $\begin{array}{l}\text { Stoichiometric } \\
\text { and almost- } \\
\text { stoichiometric } \\
\text { lithium imide }\end{array}$ \\
\hline Unknown 1 & 3258 & $-2.78(4)$ & $\begin{array}{l}\text { Lithium imide } \\
\text { in non- } \\
\text { stoichiometric } \\
\text { phase }\end{array}$ \\
\hline Unknown 2 & 3244 & $-2.78(4)$ & $\begin{array}{l}\text { Lithium am- } \\
\text { ide in non- } \\
\text { stoichiometric } \\
\text { phase }\end{array}$ \\
\hline Unknown 3 & 3291 & $-2.78(4)$ & $\begin{array}{l}\text { Lithium am- } \\
\text { ide in non- } \\
\text { stoichiometric } \\
\text { phase }\end{array}$ \\
\hline
\end{tabular}

Uncertainties in refined peak positions are all less than $1 \mathrm{~cm}^{-1}$.

Raman spectroscopy provided valuable information about the non-stoichiometric continuum, with distinct $\mathrm{N}$ $\mathrm{H}$ stretches resolved for amide and imide groups in both stoichiometric and non-stoichiometric environments. These spectra indicate that, even in the samples which appear in diffraction experiments as a single phase, there may be significant local structural variation in the sample. The peaks associated with the imide groups and the amide groups in non-stoichiometric environments exhibited a linear shift in wavenumber with changes in the average stoichiometry, while the peaks assigned to the stoichiometric amide environment groups did not vary significantly, supporting the assertion that the amide phase cannot accommodate significant variation in stoichiometry before forming the cubic structure.

\section{ASSOCIATED CONTENT}

Supporting Information. X-ray and neutron powder diffraction patterns with Rietveld analysis. Spherical harmonics coefficients. This material is available free of charge via the Internet at http://pubs.acs.org.

\section{AUTHOR INFORMATION}

\section{Corresponding Author}

* bill.david@stfc.ac.uk, josh.makepeace@chem.ox.ac.uk

\section{Author Contributions}

The manuscript was written through contributions of all authors. All authors have given approval to the final version of the manuscript.

\section{ACKNOWLEDGMENT}

Professor Martin Jones and Professor Peter Edwards are acknowledged for useful discussions. Dr Ron Smith is acknowledged for assistance collecting the neutron powder diffraction data. Dr James Taylor and Dr Gavin Stenning are acknowledged for laboratory management. The authors acknowledge ISIS Neutron and Muon Facility for the provision of experimental time on the POLARIS diffractometer and the Rigaku Smartlab diffractometer. JWM acknowledges the Rhodes Trust and St John's College, Oxford, for financial support.

\section{REFERENCES}

(1) Chen, P.; Xiong, Z.; Wu, G.; Liu, Y.; Hu, J.; Luo, W. Metal-N-H Systems for the Hydrogen Storage. Scr. Mater. 2007, 56 (10), 817-822.

(2) Gregory, D. H. Lithium Nitrides, Imides and Amides as Lightweight, Reversible Hydrogen Stores. J. Mater. Chem. 2oo8, 18 (20), 2321.

(3) Lamb, J.; Chandra, D.; Chien, W.-M.; Phanon, D.; Penin, N.; Cernyy, R.; Yvon, K. Mitigation of Hydrogen Capacity Losses during Pressure Cycling of the $\mathrm{Li}_{3} \mathrm{~N}-\mathrm{H}$ System by the Addition of Nitrogen. J. Phys. Chem. C 2011, 115 (29), 14386-14391.

(4) Osborn, W.; Markmaitree, T.; Shaw, L. L. The LongTerm Hydriding and Dehydriding Stability of the Nanoscale LiNH2+LiH Hydrogen Storage System. Nanotechnology 2009, 20 (20), 204028.

(5) David, W. I. F.; Jones, M. O.; Gregory, D. H.; Jewell, C. M.; Johnson, S. R.; Walton, A.; Edwards, P. P. A Mechanism for Non-Stoichiometry in the Lithium Amide/lithium Imide Hydrogen Storage Reaction. J. Am. Chem. Soc. 2007, 129 (6), 1594-1601.

(6) Miceli, G.; Cucinotta, C. S.; Bernasconi, M.; Parrinello, M. First Principles Study of the $\mathrm{LiNH}_{2}$ / Li2 NH Transformation. J. Phys. Chem. C 2010, 114, 15174-15183.

(7) Hoang, K.; Janotti, A.; Van de Walle, C. G. Mechanisms for the Decomposition and Dehydrogenation of Li Amide/imide. Phys. Rev. B 2012, 85 (6), 64115.

(8) Bull, D. J.; Weidner, E.; Shabalin, I. L.; Telling, M. T. F.; Jewell, C. M.; Gregory, D. H.; Ross, D. K. Pressure-Dependent Deuterium Reaction Pathways in the Li-N-D System. Phys. Chem. Chem. Phys. 2010, 12 (9), 2089-2097.

(9) Makepeace, J. W.; Jones, M. O.; Callear, S. K.; Edwards, P. P.; David, W. I. F. In Situ X-Ray Powder Diffraction Studies of Hydrogen Storage and Release in the Li-N-H System. Phys. Chem. Chem. Phys. 2014, 16, 4061-4070.

(10) Makepeace, J. W.; Wood, T. J.; Hunter, H. M. A.; Jones, M. O.; David, W. I. F. Ammonia Decomposition Catalysis Using Non-Stoichiometric Lithium Imide. Chem. Sci. 2015, 6, 38053815 .

(11) Zhang, F.; Wang, Y.; Chou, M. Theoretical Investigation of Intermediate Phases between $\mathrm{Li}_{2} \mathrm{NH}$ and $\mathrm{LiNH} 2$. Phys. Rev. B 2010, 82, 94112.

(12) Zhang, J.; Hu, Y. H. Decomposition of Lithium Amide and Lithium Imide with and without Anion Promoter. Ind. Eng. Chem. Res. 2011, 50 (13), 8058-8064.

(13) Crivello, J.-C.; Gupta, M.; Černý, R.; Latroche, M.; Chandra, D. Density Functional Study of Li4 NH and Li1.5NH1.5 as Intermediary Compounds during Hydrogenation of Li3N. Phys. Rev. B 2010, 81, 104113. 
(14) Paik, B.; Matsuo, M.; Sato, T.; Qu, L.; Wolczyk, A. R.; Orimo, S. Effect of the Structural Evolution on the Ionic Conductivity of Li-N-H System during the Dehydrogenation. Appl. Phys. Lett. 2016, 108 (21), 213903.

(15) Hu, Y. H.; Ruckenstein, E. Ultrafast Reaction between $\mathrm{Li}_{3} \mathrm{~N}$ and $\mathrm{LiNH}_{2}$ To Prepare the Effective Hydrogen Storage Material Li2NH. Ind. Eng. Chem. Res. 2oo6, 45, 4993-4998.

(16) Balogh, M. P.; Jones, C. Y.; Herbst, J. F.; Hector, L. G.; Kundrat, M. Crystal Structures and Phase Transformation of Deuterated Lithium Imide, Li2ND. J. Alloys Compd. 2006, 420 (12), 326-336.

(17) Li, W.; Wu, G.; Xiong, Z.; Feng, Y. P.; Chen, P. Li+ Ionic Conductivities and Diffusion Mechanisms in Li-Based Imides and Lithium Amide. Phys. Chem. Chem. Phys. 2012, 14 (5), 15961606.

(18) Alpen, U. v. Li3N : A Promising Li Ionic Conductor. J. Solid State Chem. 1979, 29, 379-392.

(19) Noritake, T.; Nozaki, H.; Aoki, M.; Towata, S.; Kitahara, G.; Nakamori, Y.; Orimo, S. Crystal Structure and Charge Density Analysis of Li2NH by Synchrotron X-Ray Diffraction. J. Alloys Compd. 2005, 393 (1-2), 264-268.

(20) Ohoyama, K.; Nakamori, Y.; Orimo, S.; Yamada, K. Revised Crystal Structure Model of Li2NH by Neutron Powder Diffraction. J. Phys. Soc. Japan 2005, 74 (1), 483-487.

(21) Chen, P.; Xiong, Z.; Luo, J.; Lin, J.; Tan, K. L. Interaction between Lithium Amide and Lithium Hydride. J. Phys. Chem. B 2003, 107, 10967-10970.

(22) Huq, A.; Richardson, J. W.; Maxey, E. R.; Chandra, D.; Chien, W.-M. Structural Studies of Deuteration and Dedeuteration of LizN by Use of In Situ Neutron Diffraction. J. Phys. Chem. C 2007, 111, 10712-10717.

(23) Miceli, G.; Ceriotti, M.; Angioletti-Uberti, S.; Bernasconi, M.; Parrinello, M. First-Principles Study of the HighTemperature Phase of LizNH. J. Phys. Chem. C 2011, 115, 70767080.

(24) Herbst, J. F.; Hector, L. G. Energetics of the Li Amide / Li Imide Hydrogen Storage Reaction. Phys. Rev. B 2005, 72, 125120.

(25) Mueller, T.; Ceder, G. Effective Interactions between the N-H Bond Orientations in Lithium Imide and a Proposed Ground-State Structure. Phys. Rev. B 2006, 74, 134104.

(26) Mueller, T.; Ceder, G. Ab Initio Study of the LowTemperature Phases of Lithium Imide. Phys. Rev. B 2010, 82, 174307 .

(27) Miceli, G.; Ceriotti, M.; Bernasconi, M.; Parrinello, M. Static Disorder and Structural Correlations in the LowTemperature Phase of Lithium Imide. Phys. Rev. B 2011, 83, 54119.

(28) Sørby, M. H.; Nakamura, Y.; Brinks, H. W.; Ichikawa, T.; Hino, S.; Fujii, H.; Hauback, B. C. The Crystal Structure of LiND2 and $\mathrm{Mg}\left(\mathrm{ND}_{2}\right)$ 2. J. Alloys Compd. 2007, 428 (1-2), 297-301.

(29) Yang, J. B.; Zhou, X. D.; Cai, Q.; James, W. J.; Yelon, W. B. Crystal and Electronic Structures of LiNH2. Appl. Phys. Lett. 2006, 88 (4), 41914.

(30) Kojima, Y.; Kawai, Y. IR Characterizations of Lithium Imide and Amide. J. Alloys Compd. 2005, 395 (1-2), 236-239.

(31) Bohger, J.; Essmann, R.; Jacobs, H. Infrared and Raman Studies on the Internal Modes of Lithium Amide. J. Mol. Struct. 1995, 348, 325-328.

(32) Michigoe, A.; Hasegawa, T.; Ogita, N.; Ichikawa, T.; Kojima, Y.; Isobe, S.; Udagawa, M. Raman Scattering Study of Hydrogen Storage Material LiNH2. J. Phys. Soc. Japan 2012, 81, 111.

(33) Song, Y.; Guo, Z. Electronic Structure, Stability and Bonding of the Li-N-H Hydrogen Storage System. Phys. Rev. B 2006, 74, 195120. 
Insert Table of Contents artwork here

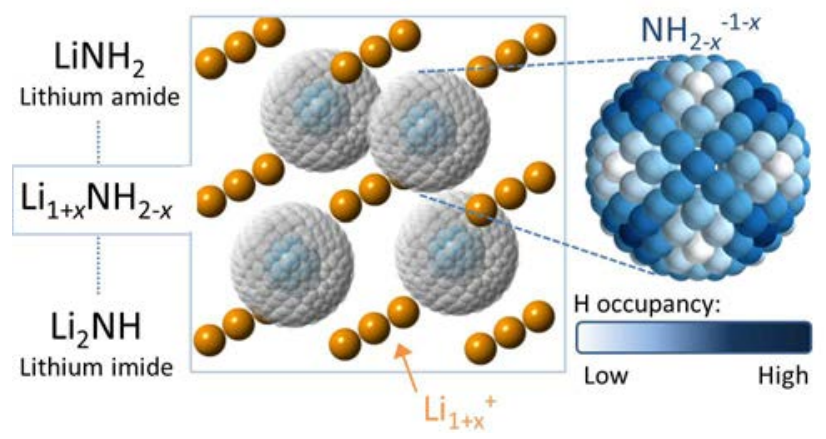

